\title{
Vascular parkinsonism: a case series of 17 patients
}

\author{
Parkinsonismo vascular: uma série de casos de 17 pacientes \\ Thiago Cardoso Vale 1 , Paulo Caramelli, ${ }^{1,2}$ Francisco Cardoso $0^{1,3}$
}

\begin{abstract}
Objective: To report the clinical and neuroimaging findings in a case series of vascular parkinsonism (VP). Methods: Seventeen patients with VP were evaluated with motor, cognitive, and neuroimaging standardized tests and scales. Results: All patients had arterial hypertension. Ten patients were male and the mean age of the whole sample was $75.8 \pm 10.1$ years. The mean age of parkinsonism onset was $72.2 \pm 10.0$ years. Common clinical features were urinary incontinence (88.2\%), lower limb parkinsonism with freezing of gait and falls (82.3\%), and pyramidal signs (76.4\%). The mean Unified Parkinson's Disease Rating Scale (UPDRS) and Hoehn-Yahr scores were $72.5 \pm 21.6$ points and $3.3 \pm 0.9$ points, respectively. Sixteen (94.1\%) patients had freezing of gait and executive dysfunction. Twelve (70.5\%) patients had probable vascular dementia. The mean dose of levodopa was $530.9 \mathrm{mg} /$ day. Unresponsiveness to the drug was confirmed by a 6.9 mean point reduction in the UPDRS score after the "practically defined off" test. Conclusion: This series provides a profile of VP with predominant lower-limb involvement, freezing of gait and falls, pyramidal signs, executive dysfunction, concomitant vascular dementia, and poor levodopa response.
\end{abstract}

Keywords: cerebrovascular disorders, dementia, movement disorders, parkinsonian disorders.

\section{RESUMO}

Objetivo: Relatar os achados clínicos e de neuroimagem em parkinsonismo vascular (PV). Métodos: Foram avaliados 17 pacientes com PV do ponto de vista motor, cognitivo e de neuroimagem através de testes e escalas padronizados. Resultados: Dos 17 pacientes, 10 (58,5\%) eram homens; a média de idade média foi 75,8 $\$ 10,1$ anos. Todos os pacientes eram hipertensos; a média de idade do início do parkinsonismo foi $72,2 \pm 10,0$ anos. Achados clínicos mais frequentes: incontinência urinária (88,2\%); parkinsonismo de membros inferiores com bloqueio de

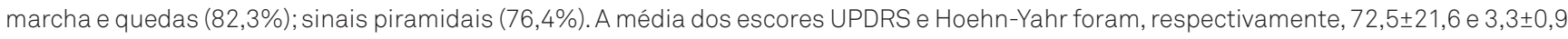
pontos. Dezesseis pacientes $(94,1 \%)$ apresentaram bloqueio de marcha e disfunção executiva. Doze pacientes $(70,5 \%)$ preencheram critérios para demência vascular provável. A dose média de levodopa foi 530,9 mg/dia e os pacientes tiveram uma baixa resposta à droga, tendo havido redução de apenas 6,9 pontos em média no escore UPDRS após o teste "practically-defined off”. Conclusão: O perfil de PV encontrado neste estudo foi caracterizado por: envolvimento predominante de membros inferiores, com bloqueio de marcha e quedas; sinais piramidais; disfunção executiva; demência vascular concomitante e resposta pobre à levodopa.

Palavras-chave: demência, transtornos cerebrovasculares, transtornos do movimento, transtornos parkinsonianos.

Vascular parkinsonism (VP) is a form of secondary parkinsonism resulting from cerebrovascular disease. The clinical picture of VP is heterogeneous and may pose significant challenges to general neurologists and to movement disorders specialists ${ }^{1}$. The diagnosis of VP has remained a controversial clinical concept since 1999 when Winikates and Jankovic first proposed its clinical criteria ${ }^{2}$. It was only in 2004 that a clinicopathological study was performed that led the authors to suggest new and stricter clinical criteria for VP; these criteria are widely used today ${ }^{3}$. However, given the many overlapping features of parkinsonian syndromes, a definitive diagnosis can only be reached by autopsy.

\footnotetext{
${ }^{1}$ Neurology Service, Hospital das Clínicas, Federal University of Minas Gerais (UFMG) and Post-graduation Program in Adult Health Applied Sciences, Faculty of Medicine, Federal University of Minas Gerais (UFMG), Belo Horizonte MG, Brazil;

${ }^{2}$ Cognitive and Behavioral Neurology Unit, Department of Internal Medicine, Faculty of Medicine, Federal University of Minas Gerais (UFMG), Belo Horizonte MG, Brazil;

${ }^{3}$ Movement Disorders Unit, Department of Internal Medicine, Faculty of Medicine, Federal University of Minas Gerais (UFMG), Belo Horizonte MG, Brazil. Correspondence: Francisco Cardoso, MD, PhD; Avenida Pasteur 89/1107;30150-290 Belo Horizonte MG - Brasil; E-mail: cardosofe@terra.com.br Conflict of interest: There is no conflict of interest to declare.

Financial support: Francisco Cardoso received research grants from Fundação de Amparo à Pesquisa do estado de Minas Gerais (FAPEMIG) and an honorarium from Roche and Moksha8. Paulo Caramelli receives research grants from CNPq (Bolsa de Produtividade em Pesquisa) and FAPEMIG.

Received 08 June 2013; Accepted 17 June 2013
} 
In various population-based studies and clinical series, VP reportedly accounted for $2.5 \%$ to $5.0 \%$ of all cases of parkinsonism ${ }^{4}$. In Brazil, Cardoso et al. ${ }^{5}$ reported that VP was present in $4.7 \%$ of 338 patients who were followed up in a tertiary care specialized movement disorder unit. In a more recent study, Munhoz et al. ${ }^{6}$ diagnosed VP in 3.9\% of patients in a large clinically based series of 1,528 patients with parkinsonism. In a community-based survey, called the Bambuí Study, 86 cases of parkinsonism were diagnosed among 1,186 study participants who were aged 64 years or older? The most frequent causes were Parkinson's disease (PD) and drug-induced parkinsonism. The third most frequent etiology was VP, which was diagnosed in $13(15.1 \%)$ patients; it had a crude prevalence rate of $1.1 \%$ (95\%CI $0.4-1.8)$.

The clinical features of VP were assessed by a recent systematic review that aimed to determine the characteristics that distinguish VP from $\mathrm{PD}^{8}$. Seven clinical studies were selected and they showed that the mean age at symptom onset was four to ten times higher in patients with VP than in patients with PD. Patients with VP more commonly presented with symmetrical gait difficulties, postural instability, falls, dementia, pyramidal signs, pseudobulbar palsy, and urinary incontinence. Patients with PD were likewise more rigid and tremulous and tended to have more hypokinesia or bradykinesia. Vascular risk factors were more common in VP than in PD. This paper is the first Brazilian case series of VP that aims to provide a clinicoradiological profile of the disease from a university setting outpatient movement disorder clinic.

\section{METHODS}

\section{Subjects}

This was a cross-sectional study of 17 patients who had a diagnosis of VP and were regularly followed-up in the Movement Disorders Outpatient Clinic of the Hospital das Clínicas of the Federal University of Minas Gerais in Belo Horizonte, Minas Gerais, Brazil. Patients had their diagnosis confirmed by applying the criteria of Zijlmans et al. ${ }^{3}$. They were selected to participate in a structured interview to identify epidemiological and clinical data such as the age and mode of onset of their parkinsonism and dementia; its clinical course; the presence of comorbidities; past medical history (especially in regard to their past cerebrovascular event); family history; use of medication; presence of adverse medication effects; presence of levodopa fluctuations and dyskinesia; presence of visual hallucination; falls; urinary incontinence; freezing of gait (FOG); and difficulties in daily living activities. A retrospective medical chart review was eventually necessary to retrieve missing information.

Patients had to fulfill Zijlmans' probable criteria for VP, which were (1) parkinsonism (defined as bradykinesia accompanied by at least one of following: rest tremor, muscular rigidity, or postural instability); (2) cerebrovascular disease, defined by evidence of relevant cerebrovascular disease, as indicated by brain imaging computed tomography (CT) or magnetic resonance imaging (MRI), or by the presence of focal signs or symptoms that are consistent with stroke; (3) a relationship between the parkinsonism and cerebrovascular disease, as ascertained by (i) an acute or delayed progressive onset with infarcts in or near areas that can increase basal ganglia motor output (e.g. the external segment of the globus pallidus or substantia nigra pars compacta) or a direct decrease in the thalamocortical drive (e.g. ventrolateral nucleus of the thalamus, large frontal lobe infarct) - the parkinsonism consists of a contralateral bradykinetic rigid syndrome or a shuffling gait that develops within one year after a stroke; or as ascertained by (ii) an insidious onset of parkinsonism with extensive subcortical white matter lesions, bilateral symptoms at onset, and the early onset of a shuffling gait or cognitive dysfunction.

Because of the heterogeneity of clinical pictures of VP, we used the Fénelon and Houéto ${ }^{9}$ classification of VP to divide it into four types, based on the clinical manifestation: (1) VP manifesting in a manner identical to PD; (2) unilateral parkinsonism after a contralateral vascular lesion; (3) "atypical" parkinsonian syndromes; and (4) "parkinsonian" gait disorders. Three categories were considered in regard to their clinical course: (1) rapidly progressive (i.e. worsening of symptoms to a nadir in less than a year after its onset); (2) stable; and (3) slowly progressive (i.e. worsening of symptoms to a nadir more than a year after its onset).

Other inclusion criteria were current use of levodopa and a Hoehn-Yahr stage of 1 to 4. Exclusion criteria included the following:

1. Evident and documented orthopedic, rheumatologic, or spinal cord disease that significantly impaired the application of motor scales and that may have otherwise posed challenges to the diagnosis;

2. Evident and documented visual abnormalities that significantly impaired the application of cognitive scales;

3. Past medical history of brain trauma or tumor;

4. Hoehn-Yahr stage 5 (i.e. wheelchair bound or bedbound), so that the patient is unable to perform the tests;

5. Diagnostic uncertainty from the medical charts review;

6. Inability of the patient to undergo neuroimaging;

7. Missing data or lack of adequate information from the patient and family; and

8. Patient's refusal to give written consent.

\section{Scales and tests}

The first version of the Movement Disorders Society Unified Parkinson's Disease Rating Scale (MDS-UPDRS) was used in the analysis of non-motor and motor symptoms of the disease ${ }^{10,11}$. Patients were examined according to Part III 
of the scale in the early morning after a 12-hour interruption from levodopa use (i.e. the "OFF" period). Immediately afterwards, the FOG scale by Giladi et al. ${ }^{12,13}$, which was recently translated into Portuguese ${ }^{14}$, was applied to all patients during the "OFF" period. Patients were instructed to use their regular diurnal dose of levodopa and were evaluated with the aforementioned scales after an hour. Response to levodopa was determined by this test - named the "practically defined off" test - initially described by the Core Assessment Program for Intracerebral Transplantations (CAPIT) ${ }^{15,16}$, in which patients had a 12-hour interruption in levodopa use. Response was based on the percentage of reduction in the MDS-UPDRS scale ${ }^{17}$ and the Hoehn-Yahr stage. Cognitive assessment was made by the Mini-Mental State Examination $(\mathrm{MMSE})^{18,19}$, the Frontal Assessment Battery (FAB) $)^{20,21}$, and the Executive Interview (EXIT25) ${ }^{22,23}$. Functional activities of daily living were assessed by the $\mathrm{Pfeffe}^{24}$ scale and the Katz scale $^{25}$. Probable vascular dementia was diagnosed based on the criteria of the National Institute of Neurological Disorders and Stroke-Association Internationale pour la Recherché et l'Enseignement en Neurosciences (NINDS-AIREN) ${ }^{26}$ and supported by the Hachinski score ${ }^{27}$. A 1.0 Tesla brain MRI was performed in all patients and fluid-attenuated inversion recovery (FLAIR), and T2- and T1-weighted sequences were used to measure the white matter burden by using the Fazekas scale ${ }^{28}$.

\section{Cut-off values}

Lower limb parkinsonism predominance was determined by a two-point difference between the upper limb and lower limb scores of bradykinesia, rigidity, and/or postural instability from Part III of the MDS-UPDRS scale. The presence of FOG was assessed by Item 14 of the MDS-UPDRS scale and by one or more points of the Giladi FOG scale, Item 3. Responders to the levodopa diurnal dose were patients who reached a percentage reduction exceeding 25\% in Part III of the UPDRS ${ }^{17}$. The MMSE scores were correlated to the number of years of schooling. Patients were considered cognitively impaired when they scored less than 21 points (for 1-3 years of schooling), less than 24 points (for 4-7 years of schooling), and less than 26 points (for 8 years or more years of schooling) ${ }^{19}$. The $\mathrm{FAB}$ scores (up to 18 points) were also subjected to variability in accordance with the formal years of schooling. Patients were considered executively dysfunctional when they scored less than 8.6 points ( for 1-3 years of schooling), less than 10.1 points (for 4-7 years of schooling), less than 11.6 points (for 8-11 years of schooling), and less than 13 points (for more than 12 years of schooling $)^{21}$. Patients were assessed by the EXIT25 scale (up to 50 points) to determine if they had executive dysfunction. Points on this scale also varied in accordance with the formal years of schooling: 5.1 points (for 1-4 years of schooling), 3.3 points ( for 5-8 years of schooling) and 2.9 points (for more than 8 years of schooling) ${ }^{23}$.

\section{Statistics and ethics}

Statistical analysis consisted of descriptive univariate analysis (mean \pm standard deviation) by using SPSS 20.1 software (IBM Corporation Software Group, USA). The study was approved by the Ethics Committee of the Federal University of Minas Gerais (Belo Horizonte, Minas Gerais, Brazil). All procedures were performed with adequate understanding and written consent of the patients or their relatives (whenever necessary).

\section{RESULTS}

Ten patients (58.8\%) were male and the mean \pm standard deviation (SD) age of the whole sample was $75.8 \pm 10.1$ years (expressed as the mean \pm standard deviation [SD]). The mean number of years of formal schooling was $2.9 \pm 2.5$ years. All patients had arterial hypertension; 10 (58.8\%) patients had dyslipidemia; and eight (47.0\%) patients had type 2 diabetes. Three (17.6\%) patients used tobacco and alcohol. Thirteen (76.4\%) patients had a previous history of lacunar stroke and developed parkinsonism within less than a month from the event. The remaining patients had an insidious onset of parkinsonism with extensive subcortical white matter disease in areas adjacent to the basal ganglia and thalamus. The mean age of onset of parkinsonism was $72.2 \pm 10.0$ years. Eight (47.0\%) patients had a rapidly progressive course of symptoms, whereas five (29.4\%) patients had stable symptoms and four (23.5\%) patients had slowly progressive symptoms. According to the aforementioned Fénelon and Houéto ${ }^{9}$ classification, we encountered patients from all groups, except the one patient in which the VP manifested in a manner identical to PD. All patients had been using levodopa for a mean period of 2.9 years and the mean dose was $530.9 \pm 218.2 \mathrm{mg} /$ day. No patient reported the usual complications of levodopa use such as dyskinesia and fluctuation.

The most common symptoms were urinary incontinence (88.2\%), lower limb parkinsonism with falls and FOG (82.3\%), and pyramidal signs $(76.4 \%)$. The mean MDS-UPDRS total score was $72.5 \pm 21.6$ points; the MDS-UPDRS Part III score was $46.3 \pm 8.0$ points; the Giladi's FOG score was $13.7 \pm 6.7$ points; and the Hoehn-Yahr stage score was $3.3 \pm 0.9$ points. The "practically-defined off" test determined a mean $6.9 \pm 4.8$ point reduction in the UPDRS scale and a mean $5.8 \pm 4.4$ point reduction in UPDRS Part III. There was no change in HoehnYahr stages between periods when patients were examined when "ON" and when "OFF" levodopa.

Cognitive assessment by the MMSE, FAB, and EXIT25 scales resulted in mean values of $16.2 \pm 5.8$ points, $3.8 \pm 3.5$ points, and $35.4 \pm 11.5$ points, respectively. Twelve $(70.5 \%)$ patients fulfilled the criteria for probable vascular dementia and had a mean Hachinski score of $9.4 \pm 2.2$ points. The mean Pfeffer's Functional Activities Questionnaire score was 
2.6 \pm 1.4 points and the mean Katz Index of Independence in Activities of Daily Living score was $15.7 \pm 7.0$ points.

Except for one patient who had a strategic lacunar infarct in the contralateral substantia nigra and two patients with only periventricular white matter lesions, most (58.8\%) patients had multiple lacunar infarcts and $23.5 \%$ of the patients had extensive white matter disease. The mean Fazekas scale of white matter burden was $2.47 \pm 0.7$ points.

\section{DISCUSSION}

In this case series, VP was mostly characterized by lower limb parkinsonism with frequent FOG and falls, urinary incontinence, pyramidal signs, and executive dysfunction with concomitant probable vascular dementia. There was no response to levodopa and most patients had multiple infarcts or an extensive white matter disease burden, as indicated by brain MRI. The onset of the movement disorder occurred in patients who were in their seventies and symptom onset was preceded by an overt cerebrovascular event - mostly lacunar - in most patients.

Because of prognostic and therapeutic implications, the most important consideration when making a diagnosis of $\mathrm{VP}$ is differentiating it from $\mathrm{PD}^{4}$. Based on a systematic review of seven clinical studies and 16 other comparative studies (which included an assessment of imaging data), patients with VP were older, had a shorter duration of the illness, presented with symmetrical gait difficulties, and were less responsive to levodopa. They were also more prone to postural instability, falls, and dementia. Pyramidal signs, pseudobulbar palsy, and urinary incontinence were also common. By contrast, patients with PD presented with upper limb asymmetrical rest tremor or bradykinesia and they had a prominent response to levodopa. Vascular risk factors were more common in patients with VP than in patients with $\mathrm{PD}^{8}$. Table 1 summarizes the seven clinical studies of VP in comparison to PD.

On brain MRI, the diagnosis of VP must be supported by the presence of diffuse white matter lesions and/or strategic subcortical infarcts. The exact pathophysiological mechanisms leading to VP are unknown, although diffuse white matter lesions may damage the net thalamocortical loop, thereby decreasing the ultimate influence of the basal ganglia on higher centers of motor planning and execution. All the same, strategic infarcts would cause parkinsonism by disrupting the putamino-pallido-thalamic loop ${ }^{1,35}$.

Notwithstanding the clinical variability, neuroimaging is also problematic. Infarctions of the basal ganglia and deep white matter occur very frequently in the elderly who do not have parkinsonism, and patients with pathologically confirmed PD may present with vascular lesions as incidental findings. Hence, a large proportion of patients with late-onset PD have some white matter changes on brain scans that may prompt physicians to incorrectly diagnose $\mathrm{VP}^{9,36}$. The association between comorbid white matter disease and PD most consistently manifests as an impairment of axial motor symptoms and executive functions; therefore a subtype of a more rapidly evolving and aggressive $\mathrm{PD}$ could misdirect physicians to a diagnosis of $\mathrm{VP}^{37}$. Most specialists would argue that differentiation would be possible by means of assessing levodopa responsiveness and olfaction. To further complicate matters, Zijlmans et al..$^{38}$ have reported good or excellent responses to levodopa in 12 of 17 patients with pathologically confirmed VP. The use of the University of Pennsylvania Smell Test may be a helpful discriminator since olfaction is apparently preserved in patients with VP, whereas $80 \%$ of patients with PD are hyposmic ${ }^{39}$.

This uncertainty and difficulty in diagnosing parkinsonian syndrome is exemplified by the study of Horvath et al. ${ }^{40}$ who investigated the clinical accuracy of diagnosis with the pathological gold standard method. The overall diagnostic accuracy in their sample was $63.4 \%$. For patients with PD, the diagnostic accuracy was $71.2 \%$ for the entire study period and increased for the ensuing decades, and reached $85.7 \%$ in the last decade. Clinical misdiagnoses included nine cases of unspecified parkinsonian syndrome, one case of postencephalitic parkinsonism, one case of progressive supranuclear palsy, three cases of VP, and one case of drug-induced parkinsonism.

This paper presented a rather typical case series of VP in which the patients had their diagnosis confirmed many times by follow-up consultations with movement disorders specialists. Our case series showed a high number of concomitant probable vascular dementia diagnosis. Unlike in patients with PD, cognitive decline can be present in VP at presentation or can develop early in the course of the disease. The dementia is usually subcortical, manifesting as dysexecutive syndrome with impairment of attention, planning, judgment, goal-directed behavior, abstract thinking, verbal fluency, and apathy. Concomitant cognitive decline or dementia has already been reported by other authors ${ }^{3,41,42}$. In the Bambuí study $^{7}$, eight (61.5\%) of 13 patients with VP presented with the concomitant diagnosis of vascular dementia. In a case series of 28 cases of pathologically confirmed VP, Glass et al. ${ }^{43}$ found concomitant dementia in $39 \%$ of the patients.

In conclusion, this case series provides a clinical and neuroimaging profile of VP. All patients had arterial hypertension and they were in their seventies when symptoms appeared. The clinical picture comprised lower limb parkinsonism with FOG and falls, pyramidal signs, executive dysfunction, and poor levodopa responsiveness. Most patients developed concomitant probable vascular dementia and had multiple infarcts or an extensive white matter burden on brain MRI. Physicians should keep this profile in mind when dealing with parkinsonism in the elderly population, especially in people with a history of stroke. 
Table 1. Clinical characteristics of vascular parkinsonism obtained from seven clinical studies (adapted from Kalra et al. ${ }^{8}$ ).

\begin{tabular}{|c|c|c|c|}
\hline Study/Year & Design & Subjects & Diagnostic criteria \\
\hline $\begin{array}{l}\text { FitzGerald and } \\
\text { Jankovic } 29 / 1989\end{array}$ & $\begin{array}{l}\text { Hospital-based } \\
\text { cross-sectional } \\
\text { (tertiary referral } \\
\text { center) }\end{array}$ & $\begin{array}{l}10 \mathrm{VP} \\
100 \mathrm{PD}\end{array}$ & $\begin{array}{l}\text { Marked gait difficulty with } \\
\text { lack of or with only minimal } \\
\text { upper limb involvement } \\
\text { (i.e. lower body } \\
\text { parkinsonism) }\end{array}$ \\
\hline $\begin{array}{l}\text { Zijlmans } \\
\text { et al. }{ }^{30 / 1995}\end{array}$ & Cross-sectional & $\begin{array}{l}15 \mathrm{VP} \\
15 \mathrm{DP}\end{array}$ & $\begin{array}{l}\text { Parkinsonism with dominant } \\
\text { frontal gait disorder, } \\
\text { aged }>60 \text { years, and the } \\
\text { exclusion of other secondary } \\
\text { parkinsonism types }\end{array}$ \\
\hline
\end{tabular}

$\begin{array}{lr}\text { Yamanouchi and } & \text { Clinicopathological } \\ \text { Nagura } \mathrm{VP}^{31} / 1997 & 30 \mathrm{PD}^{\circ}\end{array}$

Winikates and

Jankovic $2 / 1999$

et al. ${ }^{32} / 2001$
Retrospective, $\quad 69 \mathrm{VP}$ cross-sectional, $\quad 277 \mathrm{PD}$ hospital-based

Review of medical records, cross-sectional

Parkinsonism, presence of vascular lesions on brain $\mathrm{MRI}$, and the exclusion of other causes of secondary parkinsonism

Patients with parkinsonism and a vascular score of 2 points or more on a vascular rating scale ${ }^{a}$$$
\text { parkinsonism }
$$

$39 \mathrm{VP}$ $28 P^{b}$

\section{Hospital-based} cohort

et al. ${ }^{33} / 2005$
Cross-sectional

$55 \mathrm{VP}$ $132 \mathrm{PD}$

\begin{abstract}
Lower body parkinsonism with frontal gait disorder, postural instability, lack of resting tremor, symmetrical progression, poor response to levodopa, and multiple basal ganglia or subcortical infarctions
\end{abstract}

Clinical findings

Patients with VP have a significantly shorter symptom duration, present with gait difficulty, have less levodopa responsiveness. There is no difference in risk factors, except for hypertension.

There is no difference between patients with VP and patients with PD or hypertensive controls in age or BP. Patients with VP have more subcortical lesions than patients with PD. A cutoff of $0.6 \%$ lesioned ischemic brain volume is suggested. Clinical severity is not correlated with lesion volume or location.

Of the patients with VP, $17 \%$ of the patients had tremor (versus 73\% of the PD patients), 38\% of the patients had hemiparesis, and $63 \%$ of the patients had pyramidal signs (versus $0 \%$ in the PD patients). One-half of the patients with VP had pseudobulbar palsy; $27 \%$ of patients with PD had dysphasia or dysarthria. Dementia was present in $71 \%$ of patients with VP and $43 \%$ of patients with PD. Only one-fifth of the patients with VP showed a transient response to levodopa. Asymmetry of limb rigidity was present in $29 \%$ of the patients with VP versus $73 \%$ of the patients with PD. There was no difference in gait disorders between VP and PD.

Patients with VP were significantly older and had gait difficulty, less levodopa responsiveness, symmetrical predominant lower body involvement, postural instability, falls, dementia, corticospinal findings, incontinence, and pseudobulbar palsy.

Patients with VP were significantly older, had a shorter disease duration, had a gait disorder as the most frequent initial symptom, and $38 \%$ of the patients were levodopa responsive. Vascular risk factors were more common in patients with VP. Postural instability, freezing, gait disturbance, pyramidal signs, postural tremor were significantly more prevalent in VP. Patients with VP have more prominent features in the lower limbs.

Patients with VP were older and $29 \%$ of the patients were levodopa responsive. Vascular risk factors, postural tremor, gait disorder, pyramidal signs, and lower body predominance more frequent in VP. The UPDRS scores at baseline were higher in patients with VP than in patients with PD. After 2 years, patients with VP had greater lower limb involvement than patients with PD.

There was no difference in age or MMSE score between patients with VP, PD, and hypertensive controls. Primitive reflexes (i.e. snout,

palmomental), jaw jerk, Hoffmann's score, and extensor plantar response were significantly higher in VP.

aascular rating scale: 2 points for pathologically or angiographically proven diffuse vascular disease; 1 point for the onset of parkinsonism within 1 month of clinical stroke; 1 point for a history of two or more strokes; 1 point for a history of two or more risk factors of stroke; and 1 point for neuroimaging evidence of vascular disease in two or more vascular territories ${ }^{2}$.

bOnly patients older than 70 years were included.

'These patients included 22 age-matched Binswanger's disease patients without parkinsonism.

BP: blood pressure; MMSE: Mini-Mental State Examination; MR: magnetic resonance imaging; PD: Parkinson's disease; UPDRS: Unified Parkinson's Disease Rating Scale; VP: vascular parkinsonism. 
1. Vale T, Barbosa MT, Caramelli P, Cardoso F. Vascular Parkinsonism and cognitive impairment: literature review, Brazilian studies and case vignettes. Dement Neuropsychol 2012;6:137-144.

2. Winikates J, Jankovic J. Clinical correlates of vascular parkinsonism. Arch Neurol 1999;56:98-102.

3. Zijlmans JC, Daniel SE, Hughes AJ, Revesz T, Lees AJ. Clinicopathological investigation of vascular parkinsonism, including clinical criteria for diagnosis. Mov Disord 2004;19:630-640.

4. Gupta D, Kuruvilla A. Vascular parkinsonism: what makes it different? Postgrad Med J 2011;87:829-836.

5. Cardoso F, Camargos ST, Silva GA Jr. Etiology of parkinsonism in a Brazilian movement disorders clinic. Arq Neuropsiquiatr 1998;56:171-175.

6. Munhoz RP, Werneck LC, Teive HA. The differential diagnoses of parkinsonism: findings from a cohort of 1528 patients and a 10 years comparison in tertiary movement disorders clinics. Clin Neurol Neurosurg 2010;112:431-435.

7. Barbosa MT, Caramelli P, Maia DP, et al. Parkinsonism and Parkinson's disease in the elderly: a community-based survey in Brazil (the Bambui study). Mov Disord 2006;21:800-808

8. Kalra S, Grosset DG, Benamer HT. Differentiating vascular parkinsonism from idiopathic Parkinson's disease: a systematic review. Mov Disord 2010;25:149-156.

9. Fenelon G, Houeto JL. Vascular Parkinson syndromes: a controversial concept [in French]. Rev Neurol (Paris) 1998;154:291-302.

10. Fahn S, Elotion R; UPDRS Program Members. Unified Parkinson's disease rating scale. vol 2. Florham Park, NJ: Macmillan Healthcare Information, 1987.

11. Ramaker C, Marinus J, Stiggelbout AM, Van Hilten BJ. Systematic evaluation of rating scales for impairment and disability in Parkinson's disease. Mov Disord 2002;17:867-876.

12. Giladi N, McDermott MP, Fahn S, et al. Freezing of gait in PD: prospective assessment in the DATATOP cohort. Neurology 2001;56:1712-1721.

13. Giladi N, Tal J, Azulay T, et al. Validation of the freezing of gait questionnaire in patients with Parkinson's disease. Mov Disord 2009;24:655-661.

14. Baggio JA, Curtarelli MB, Rodrigues GR, Tumas V. Validity of the Brazilian version of the freezing of gait questionnaire. Arq Neuropsiquiatr 2012;70:599-603.

15. Langston JW, Widner H, Goetz CG, et al. Core assessment program for intracerebral transplantations (CAPIT). Mov Disord 1992;7:2-13.

16. Kompoliti K, Cornelia CL, Goetz CG. Clinical Rating Scales in Movement Disorders. In Jankovic $J$ and Tolosa E (ed). Parkinson's Disease and Movement Disorders. 2006; 5th ed, pp. 692-701. Philadelphia: Lippincott Williams and Wilkins.

17. Clarke CE, Davies P. Systematic review of acute levodopa and apomorphine challenge tests in the diagnosis of idiopathic Parkinson's disease. J Neurol Neurosurg Psychiatry 2000;69:590-594.

18. Folstein MF, Folstein SE, McHugh PR. "Mini-mental state". A practical method for grading the cognitive state of patients for the clinician. J Psychiatr Res 1975;12:189-198.

19. Brucki SM, Nitrini R, Caramelli P, Bertolucci PH, Okamoto $\Vdash H$. Suggestions for utilization of the mini-mental state examination in Brazil [article in Portugese]. Arq Neuropsiquiatr 2003;61:777-781.

20. Dubois B, Slachevsky A, Litvan I, Pillon B. The FAB: a Frontal Assessment Battery at bedside. Neurology 2000;55:1621-1626.

21. Beato R, Amaral-Carvalho V, Guimaraes HC, et al. Frontal assessment battery in a Brazilian sample of healthy controls: normative data. Arq Neuropsiquiatr 2012;70:278-280.

22. Royall DR, Mahurin RK, Gray KF. Bedside assessment of executive cognitive impairment: the executive interview. J Am Geriatr Soc 1992;40:1221-1226

23. Matioli MNPS, Caramelli P, Marques BD, et al. EXIT25 - executive interview applied to a cognitively healthy elderly population with heterogeneous educational background. Dement Neuropsychol 2008;2:305-309.

24. Pfeffer RI, KurosakiTT, Harrah CHJr., ChanceJM, Filos S. Measurement of functional activities in older adults in the community. J Gerontol 1982;37:323-329.

25. Katz S, Downs TD, Cash HR, Grotz RC. Progress in development of the index of ADL. Gerontologist 1970;10:20-30.

26. Roman GC, Tatemichi TK, Erkinjuntti T, et al. Vascular dementia: diagnostic criteria for research studies. Report of the NINDS-AIREN International Workshop. Neurology 1993;43:250-260.

27. Moroney JT, Bagiella E, Desmond DW, et al. Meta-analysis of the Hachinski Ischemic Score in pathologically verified dementias. Neurology 1997;49:1096-1105.

28. Fazekas F, Chawluk JB, Alavi A, Hurtig HI, Zimmerman RA. MR signal abnormalities at 1.5 T in Alzheimer's dementia and normal aging. AJR Am J Roentgenol 1987;149:351-356.

29. FitzGerald PM, Jankovic J. Lower body parkinsonism: evidence for vascular etiology. Mov Disord 1989;4:249-260.

30. Zijlmans JC, Thijssen HO, Vogels OJ, et al. MRI in patients with suspected vascular parkinsonism. Neurology 1995;45:2183-2188.

31. Yamanouchi $\mathrm{H}$, Nagura H. Neurological signs and frontal white matter lesions in vascular parkinsonism. A clinicopathologic study. Stroke 1997;28:965-969.

32. Demirkiran M, Bozdemir H, Sarica Y. Vascular parkinsonism: a distinct, heterogeneous clinical entity. Acta Neurol Scand 2001;104:63-67.

33. Rampello L, Alvano A, Battaglia G, Raffaele R, Vecchio I, Malaguarnera M. Different clinical and evolutional patterns in late idiopathic and vascular parkinsonism. J Neurol 2005;252:1045-1049.

34. Okuda B, Kawabata K, Tachibana H, Kamogawa K, Okamoto K. Primitive reflexes distinguish vascular parkinsonism from Parkinson's disease. Clin Neurol Neurosurg 2008;110:562-565.

35. Murrow RW, Schweiger GD, Kepes JJ, Koller WC. Parkinsonism due to a basal ganglia lacunar state: clinicopathologic correlation. Neurology 1990;40:897-900.

36. Hughes AJ, Daniel SE, Blankson S, Lees AJ. A clinicopathologic study of 100 cases of Parkinson's disease. Arch Neurol 1993;50:140-148.

37. Lee SJ, Kim JS, Yoo JY, et al. Influence of white matter hyperintensities on the cognition of patients with Parkinson disease. Alzheimer Dis Assoc Disord 2010;24:227-233.

38. Zijlmans J, Evans A, Fontes F, et al. [123I] FP-CIT spect study in vascular parkinsonism and Parkinson's disease. Mov Disord 2007;22:1278-1285.

39. Katzenschlager R, Zijlmans J, Evans A, Watt H, Lees AJ. Olfactory function distinguishes vascular parkinsonism from Parkinson's disease.J Neurol Neurosurg Psychiatry 2004;75:1749-1752.

40. Horvath J, Burkhard PR, Bouras C, Kovari E. Etiologies of Parkinsonism in a century-long autopsy-based cohort. Brain Pathol 2013;23:28-33.

41. Stenc Bradvica I, Janculjak D, Butkovic-Soldo S, Vladetic M. Cognitive dysfunction in idiopathic and vascular parkinsonism. Med Glas (Zenica) 2011;8:209-215

42. Santangelo G, Vitale C, Trojano L, et al. Differential neuropsychological profiles in Parkinsonian patients with or without vascular lesions. Mov Disord 2010;25:50-56.

43. Glass PG, Lees AJ, Bacellar A, Zijlmans J, Katzenschlager R, SilveiraMoriyama L. The clinical features of pathologically confirmed vascular parkinsonism. J Neurol Neurosurg Psychiatry 2012;83:1027-1029. 